ISSN 1981-416X

Licenciado sob uma Licença Creative Commons

\title{
Estado democrático e a concepção de democracia e representatividade nos Conselhos Municipais de Educação no Brasil
}

\author{
Democratic State and the conception \\ of democracy and representativeness \\ in Municipal Councils of Education in Brazil
}

Estado democrático y la concepción de democracia

y representatividad en los Consejos Municipales

de Educación en Brasil

\section{Antonio Bosco de Lima, Ari Raimann, Fernando dos Santos*}

Universidade Federal de Uberlândia, Uberlândia, MG, Brasil

Universidade Federal de Goiás, Jataí, GO, Brasil

\section{Resumo}

O artigo problematiza a questão da representatividade presente nos Conselhos Municipais de Educação. Para seu desenvolvimento, os autores explicitam a concepção de Estado democrático burguês. Num primeiro momento destacam a relação entre Estado, democracia, representatividade e participação realizada a partir de pesquisa bibliográfica. $\mathrm{Na}$

*ABL: Doutor em Educação, e-mail: boscodelima@gmail.com

AR: Doutor em Educação, e-mail: raimann04@gmail.com

FS: Mestre em Educação, e-mail: fernandosantos.ufg@gmail.com 
segunda parte, focam a experiência vivenciada sobre função e papel dos conselheiros nos Conselhos Municipais de educação (CMEs), com base em pesquisa realizada a partir de dois encontros nacionais sobre conselhos municipais de educação no Brasil. O primeiro realizado na Cidade de Jataí/GO e o segundo realizado na cidade de Uberaba/MG. Destacam que as atividades dos conselheiros situam-se num campo de disputa, na qual os Conselhos institucionalizados tendem a reproduzir as relações hierarquizadas das Secretarias de Educação Municipal, entretanto os Conselhos não se fundamentam apenas num papel de mera representação, pois os conselheiros têm história de vida, política e social diferenciada, o que faz com que não reproduzam simplesmente o que a secretaria requer. Isto suscita em cada conselho uma história, a qual está vinculada ao seu local, aos movimentos sociais daquela cidade, à organização societal daquele povo, enfim, à construção educacional e cultural que recolhe um papel diferenciado a cada Conselho.

Palavras-chave: Estado. Democracia. Conselho Municipal de Educação. Representatividade. Participação.

\begin{abstract}
The article problematizes the question of representativeness present in Municipal Councils of Education. For its development, the authors explain the concept of bourgeois Democratic State. In the first moment, they highlight the relationship between State, democracy, representativeness and participation, starting from a bibliographical research. In the second part, they focus on the experience gained on the role and function of counselors in the Municipal Councils of Education (CMEs), based on a research conducted from two national meetings on municipal education councils in Brazil. The first one was held in the city of Jatai / GO and the second one was held in the city of Uberaba / MG. They emphasize that the counselor's activities are held in a field of dispute, in that the institutionalized Councils tend to reproduce the hierarchical relations of the Municipal Education Departments; however, the Councils are not based only on a simple role of representation, since the counselors have a differentiated social, political, and life history, meaning that they do not simply reproduce what the department requires. This gives rise to a history in each council, that is linked to its place, to the
\end{abstract}


social movements of that city, to the societal organization of that people, and finally to the educational and cultural construction that takes on a different role for each Council.

Keywords: State. Democracy. Municipal Council of Education. Representativity. Participation.

\section{Resumen}

Este artículo de investigación problematiza la cuestión de la representatividad presente en los Consejos Municipales de Educación. Para su desarrollo, los autores explicitan la concepción de Estado democrático burgués. En un primer momento destacan la relación entre Estado, democracia, representatividad y participación realizada a partir de la investigación bibliográfica. En la segunda parte se enfoca la experiencia vivenciada sobre función y papel de los consejeros en los Consejos Municipales de Educación (CMEs), con base en investigación realizada a partir de dos encuentros nacionales sobre Consejos Municipales de Educación en Brasil. El primero realizado en la ciudad de Jataí/GO y el segundo realizado en la ciudad de Uberaba/MG. Destacan que las actividades de los consejeros se sitúan en un campo de disputa, en la cual los Consejos institucionalizados tienden a reproducir las relaciones jerarquizadas de las Secretarías de Educación Municipal, sin embargo los Consejos no se fundamentan apenas en un papel de mera representación, pues los consejeros tienen historia de vida, política y social diferenciada, lo que hace que los mismos no reproduzcan simplemente lo que la secretaría requiere. Esto suscita en cada consejo una historia, la cual está vinculada a su lugar, a los movimientos sociales de aquella ciudad, a la organización societal de aquella población, en fin, a la construcción educativa y cultural que recoge un papel diferenciado a cada Consejo.

Palabras clave: Estado. Democracia. Consejo Municipal de Educación. Representatividad. Participación. 


\section{Introdução}

O foco central do presente artigo situa a problematização da representatividade presente nos Conselhos Municipais de Educação. Seu Desenvolvimento é estabelecido a partir das concepções de Estado e da democracia representativa, explicitadas no decorrer da primeira parte deste trabalho, a partir de pesquisa bibliográfica.

Em um segundo momento, os autores apresentam as experiências vivenciadas sobre função e papel dos conselheiros nos Conselhos Municipais de educação (CMEs), tecendo relações entre os dados resultantes de pesquisa as fomentações teóricas abordadas nas concepções de representatividade e participação. As informações relativas aos conselheiros foram sistematizadas com base na pesquisa realizada a partir de dois encontros nacionais sobre conselhos municipais de educação ${ }^{1}$. O primeiro realizado na Cidade de Jataí/ GO e o segundo realizado na cidade de Uberaba/MG.

A principal consideração que os autores chegam revela que as atividades dos conselheiros não estão situadas apenas no campo da reprodução das relações sociais e educativas, na qual os Conselhos, por serem institucionalizados, tendem a reproduzir relações hierarquizadas das Secretarias de Educação Municipal. Não se resume a este modelo, mas situam-se num espaço em disputa, apresentam papeis de resistência e problematizações, não se fundamentando apenas em uma lógica de representação simplista.

Os conselheiros têm história de vida, política e experiências em comunidade diferenciadas, o que faz com que os mesmos não reproduzam simplesmente o que a secretaria requer, ou seja, não são uma massa homogenia de repercussão. Isto implica que cada conselho tenha uma história,

1 Os encontros nacionais estavam previstos na pesquisa desenvolvida nacionalmente intitulada $\mathrm{O}$ Conselho Municipal de educação no Brasil e a qualidade socialmente referenciada do ensino, Chamada Universal - MCTI/CNPq $n$ 14/2014. Foram realizados quatro encontros nacionais intitulados Encontros nacionais sobre Conselhos Municipais de Educação (ENCMEs). O primeiro em Uberlândia/MG, em abril de 2016, o segundo em Jataí/GO, em outubro de 2016, o terceiro em Dourados/MS, em maio de 2017 e o quarto em Uberaba/MG, em novembro de 2017. 
a qual está vinculada ao seu lugar, aos movimentos sociais daquela cidade, à organização societal daquele povo, enfim à construção educacional e cultural, o que recolhe um papel diferenciado a cada Conselho.

\section{Estado, forma política e os limites da democracia}

Avançar na compreensão do Estado, sua forma e expressão política, além de seus limites para o atendimento de políticas sociais e problematizar as atuais características do Estado, em períodos de ataques aos direitos historicamente conquistados, equivalem à construção de alternativas que ultrapassem as experiências políticas de ocupação de espaços institucionais. Referimo-nos àquelas que foram inauguradas pelos governos socialdemocratas ou mesmo de características socialistas, seja na Europa do início do século XX ou mesmo na América Latina no limiar do século XXI.

Mais do que discutir as políticas públicas nos marcos da "eficiência e eficácia na resolução de problemas sociais", seja na esfera da conquista e ampliação de direitos ou mesmo como resposta às demandas e pressões da classe trabalhadora, nossa intenção, inicialmente, é discutir o papel do Estado e limites na constituição de um estado de bem-estar social que garanta, por períodos duradouros, o atendimento a demandas sociais e a constituição dessas políticas como direitos sociais, sendo o Estado uma esfera pacífica e de mediação e "desprovido de interesses e de luta de classes” (BEHRING; BOSCHETTI, 2011, p. 37).

Para responder a essa primeira assertiva é preciso questionar qual o caráter e validade desse atendimento em períodos de reforma do Estado, sob a égide das políticas neoliberais, de ataques aos direitos e destruição do estado de bem-estar social no centro e na periferia do modo de produção capitalista. Imprescindível questionar o papel dos canais legítimos de participação, no caso presente, os Conselhos Municipais de Educação, problematizando seu devir histórico.

Ao assumir essa difícil tarefa de análise do Estado - em sua feição capitalista - não se pode desprezar os esforços na interpretação 
do desenvolvimento das forças produtivas sob o capitalismo contemporâneo, a reestruturação permanente de seus mecanismos de concentração e apropriação das riquezas e sua forma rarefeita de distribuição. Assim, analisar também as demandas e o atendimento às políticas sociais, na nossa perspectiva, deve partir do pressuposto de que essa esfera social se insere num complexo e contraditório modo de produção, reproduzindo socialmente sob múltiplas determinações causais e inseridos numa totalidade concreta, ou seja, a interpretação do Estado a partir do prisma da crítica da economia política.

Partindo desse pressuposto, temos em Karl Marx e Friedrich Engels nossas primeiras referências na análise crítica do papel do Estado e é na produção teórica de ambos que encontraremos, ao lado de outros conceitos, que o Estado em sua faceta liberal, corresponde para essa vertente do pensamento clássico ao mediador das vontades individuais. Os mesmos autores apresentaram as motivações para a superação desta equivocada interpretação de vertentes liberais do pensamento econômico dos séculos XVIII e XIX. Destacamos aqui a passagem de Engels - na Introdução para A guerra civil na França, na qual aponta que o "Estado não é mais do que uma máquina para a opressão de uma classe por outra" (ENGELS, 2011, p. 197).

Seja na perspectiva das liberdades individuais e do livre mercado consolidada pelo pensamento liberal clássico, sem nenhuma ou pouca intervenção estatal, ou mesmo a partir de suas etapas de revisão e reorientação produtiva no início do século XX, sob a influência Keynesiana para o centro do modo de produção e orientação neoliberal na sua periferia, o capitalismo contemporâneo tem se mostrado dinâmico na busca por mecanismos que possam garantir a manutenção de suas taxas de lucro e a superação de suas crises estruturais e cíclicas.

Para Lima (2011), a configuração atual do modo de produção capitalista e do papel do Estado nas últimas três décadas tem demonstrado um gradual afastamento das concepções críticas, que apontam as ações do Estado como mecanismo que "concretiza-o como interesse das classes dominantes" e repele a "tese de arena em disputa" se 
identificando ideologicamente de forma mais contundente com as tendências que transitam da concepção liberal do Estado como "ente acima das classes e mediador da barbárie, que preconiza a solução dos problemas gerados pela própria ordem capitalista como possíveis de serem equacionados" pela ação reguladora do mercado, até aquelas que vislumbram ainda alguma possibilidade, cada vez mais limitada, de criação de um Estado de bem-estar social tendo nas políticas públicas compensatórias as saídas para minimizar os efeitos devastadores das crises estruturais do capital (LIMA, 2011, p. 20).

Avançar na interpretação do Estado torna-se tarefa primordial para compreender os limites da participação política e da luta de classes que prevalece, ainda que seja negada por correntes teóricas e concepções de lutas e resistência.

Para Mészáros (2015) a relação capital, trabalho e Estado são indissociáveis e a superação de suas determinações — ou da montanha que devemos conquistar - é a tarefa que se impõe as classes subalternas.

Ao analisar a conjuntura política no Brasil a partir da transição da ditadura empresarial-militar e seu caráter autocrático no início da década de 1980 e a transição para a democracia representativa limitada que se estabelece desde então é possível compreender a consolidação da opção pela disputa do Estado e da emergência da concepção de sociedade civil que estabelece relação com o conceito de reforma do Estado.

Iasi (2017) destaca que para entendermos a conformação da disputa conceitual sobre o Estado é também necessário compreender a movimentação em torno dos conceitos de democracia, representação e participação política que se expressaram como ideias políticas. Para uma melhor compreensão, Iasi retoma as formulações de Duriguetto (2007) quanto às posições sobre a reforma do Estado, dividindo-as inicialmente em dois blocos, sendo um primeiro bloco do conservadorismo reformista e um segundo bloco reformista de esquerda.

No primeiro bloco estariam as formulações e análises de autores como Wanderley Guilherme dos Santos, Fernando Henrique Cardoso e Bolívar Lamounier, criticando "a concentração de poder, econômico e 
político, contrapondo a esta uma liberalização do mercado e um processo de desconcentração do poder político pelo fortalecimento da sociedade civil", podendo aumentar o controle sobre as políticas públicas e as ações estatais (IASI, 2017, p. 243).

O segundo bloco, composto por autores como Carlos Nelson Coutinho, Francisco Weffort e Marilena Chauí, distingue-se do primeiro pela crítica ao Estado e pela formulação de uma meta socialista, seja na perspectiva do fortalecimento da sociedade civil como expressão de um momento da luta de classes e participação popular e aprimoramento da democracia, ou mesmo na perspectiva de criação de novos espaços políticos para apresentação de reivindicações ao Estado.

Iasi (2017) chama a atenção para a conformação da ideia de consenso que ganharia cada vez mais força, mesmo nos blocos caracterizados por uma visão mais crítica quanto ao funcionamento do Estado, fortalecendo assim as concepções que dialogam com a necessidade da ampliação do controle social.

Não é apenas a interpretação do caráter da democracia restrita e dos seus limites quanto à participação política na transição da autocracia burguesa em sua feição militarizada que estavam (ou deveria estar) em jogo, mas, sim, a própria concepção de Estado.

Coincidentemente foram esses dois blocos que se revezaram na direção do Estado brasileiro nas últimas três décadas após a Constituição Federal de (1988) e implementaram, de forma mais ou menos incisiva, as reformas do aparelho estatal (previdenciária, política, fiscal, trabalhista e educacional) que foram alçadas como prerrogativa para a democratização do Estado. O primeiro bloco, com participação mais marcante a partir do final do governo Collor de Melo (1990-1992) e durante todo o governo Franco (1992-1994) aprofundado nos dois governos Cardoso (1995-1998 e 1999-2002). Já o segundo bloco passa a participar mais intensamente da formulação das políticas públicas no âmbito do Estado a partir dos governos Lula (2003-2006 e 2007-2010) e dos governos Roussef (2011-2014 e 2015-2016). 
Chegamos, então, num dos dilemas colocados em xeque pelos limites da representatividade e da participação política, da crença na frágil democracia burguesa e da participação instrumental das frações da classe trabalhadora no que diz respeito à direção do Estado capitalista.

Entendemos que a forma política assumida pelo Estado reforça a dinâmica do modo de produção capitalista, mas não se converte em um aparato soberano per si. Para Mascaro (2013), o Estado não pode ser identificado exclusivamente como um centro único na dinâmica do modo de produção e suas relações de produção, pois o mesmo, ao seu modo, "corrobora por alimentar a dinâmica da valorização do valor" as interações sociais dos capitalistas e trabalhadores (MASCARO, 2013, p. 20).

Ainda para esse autor, as derivações da forma política estatal estão intimamente ligadas às formas de expressão econômica, mas não compõem um todo harmônico, mas antes o contrário. É nesse conflito que se expressam as antagônicas relações sociais, corporificada pelo movimento das lutas de classes.

Isso demonstra alguns limites da dinâmica da luta de classes no Brasil, da interpretação quanto ao funcionamento e caráter classista do aparato estatal, democracia e participação política. Diante desse cenário, Fernandes aponta que a hegemonia burguesa não se constitui apenas pelo seu poder de político, econômico e social, mas também pela capacidade de mobilizar, a seu favor, meios de "cooptação, opressão e repressão" (1976, p. 296).

Finalmente, ao esbarrarmos nos limites da interpretação do Estado e do conceito de democracia, sua forma de expressão política e possibilidades de participação e controle social nos aproximamos dos apontamentos de Mészáros (2015, p. 29) segundo o qual a "materialidade do Estado está profundamente enraizada na base sociometabólica" sobre a qual se ergue todo o aparato estatal, "inseparáveis tanto da materialidade do capital quanto do trabalho".

Não por acaso, o autor nos alerta que não é suficiente "escalar a montanha”, mas entender que a resolução de suas contradições pode não estar dentro apenas de suas limitações institucionais. E essa a perigosa montanha 
que confronta a humanidade é a totalidade combinada de determinações estruturais do capital que, segundo Mészáros, deve ser conquistada.

Considerando estes destaques, passaremos a analisar nas duas seções seguintes os dados das pesquisas realizadas com os Conselhos Municipais de Educação em Goiás e Minas Gerais.

\section{Conselhos do Estado de Goiás, participação e representatividade}

Conceitos de participação e representatividade estão sempre presentes no debate sobre a democracia brasileira. Como ressaltado anteriormente, no entanto, tais aspectos no processo de democratização no Brasil se dão a partir do modelo de democracia burguesa, na qual são vistas como legítimas a partir de órgãos representativos do Estado, nas chamadas instituições híbridas, que reúnem Estado e sociedade (AVRITZER; PEREIRA, 2005).

No processo de redemocratização no Brasil, verificou-se que a participação social conquistou lugar de destaque nos debates, fortalecendo a sociedade ao mesmo tempo em que qualificava os processos do Estado, dando à sociedade a ideia de ampla democracia.

Por sua vez, a representatividade passa a ganhar força, pois esta dará às instituições do Estado a imagem de organismos democráticos. Verifica-se uma tendência de modernização do Estado, mas esta mostra-se conservadora, pois suas expressões de representação política assumem tais características não apenas nas frações burguesas, mas estarão fortemente presentes nos instrumentos de organização da classe trabalhadora e nas suas lutas, tendo em vista o atendimento de suas demandas por políticas sociais. Os Conselhos Municipais de Educação apresentam-se ser organizações estatais, embora abram suas portas para determinada representatividade civil.

A seguir trataremos dos dados colhidos na pesquisa junto aos CMEs de Goiás. Importante é ressaltar que tais dados foram coletados após a participação em eventos realizados pelos conselhos, dois regionais e um estadual, culminando com a realização do ENCME II, realizado 
em Jataí. Esse movimento possibilitou que chegássemos aos CMEs do Estado, tendo sido o formulário de pesquisa composto por vinte e uma questões objetivas e abertas, das quais, considerando os limites deste texto, apenas quatro serão tratadas. Ao todo foram 59 respostas, cada uma de um CME do Estado de Goiás.

Quando indagados sobre formação, dos respondentes, 91,5\% são graduados, a maioria em alguma licenciatura. Os demais, 8,5\% são técnicos. Percebe-se a predominância de professores na composição dos CMEs, o que aponta para uma possibilidade representativa das demandas sociais muito interessante. No entanto, um dado coletado dá conta de mostrar que dentre os que representam a comunidade, $23,7 \%$ são secretários municipais de educação e 16,9\% são coordenadores pedagógicos da SME. Ao somarmos os percentuais que representam as Secretarias Municipais de Educação (SMEds), temos um percentual de 40,8\% dos conselheiros representando o sistema, o que revela uma tendência de controle acentuada. Mostrando que o "Estado não é mais do que uma máquina para a opressão de uma classe por outra" (ENGELS, 2011, p. 197).

Não bastasse isso, temos outro dado que pode ser analisado de variadas formas: os CMEs respondentes informam que $54,2 \%$ dos conselheiros são professores que atuam nas escolas públicas. Ora, este dado ao mesmo tempo que pode revelar um potencial significativo de liderança em favor das demandas sociais, pode também mostrar que este percentual pode ser cooptado para atuar como figurante, atuando em favor do sistema.

Chama a atenção o fato de $71,1 \%$ dos conselheiros respondentes terem mais de 16 anos de experiência na docência. Tal dado revela que estão ocupando as cadeiras dos CMEs docentes experientes, pressupondo-se que conheçam a realidade das escolas, podendo lutar pela melhoria da educação socialmente referenciada. Tal possibilidade, no entanto, não se coloca como garantia, uma vez que, sendo do sistema, as chances de votarem contra o mesmo é pequena pela forma como o Estado se organiza na democracia burguesa. Digno de nota também é que dois conselheiros não tinham nem um ano completo de docência. 
Indagação que foi considerada muito importante, deu conta de verificar a função que exerce o presidente do CME. A pesquisa revelou que $44 \%$ ocupam a função de docente; $15,2 \%$ são coordenadores pedagógicos nas escolas; um presidente é coordenador pedagógico da SMEd; 4 presidentes são diretores de escola pública e 1 deles é diretor de escola particular. Dentre esses dados, chama atenção também que de todos os presidentes, apenas 2 estão à disposição do $\mathrm{CME}$, o que significa que atuam 8 horas diárias na função.

Assim sendo, os dados apontam para uma tendência de que a presidência do CME seja exercida por quem é professor. Quando este é servidor público, quais seriam as chances de avanços no sentido de se apontar problemas que precisam ser corrigidos? Como atacar o sistema no qual se atua sem ser penalizado por ele? Parece ser uma outra forma de poder exercido pelo Estado democrático burguês. Até uma cartorária ocupa a presidência do CME.

A questão que tinha por objetivo coletar informações sobre como o CME foi constituído demonstrou que a sua composição ainda é decorrente de pressões políticas e de força do Estado. Do total, 11,8\% são indicados pelo prefeito; 10,1\% são indicações do Secretário Municipal de Educação; $47,4 \%$ indicaram que o Conselho é composto via eleições. Depreende-se que as eleições ocorrem entre os indicados, cabendo à comunidade indicar seus representantes, mas apenas 16,9\% revelaram essa opção.

Conforme Alves (2011), observa-se um problema de paridade na representação que ocorre nos Conselhos, quando os que representam a sociedade civil são em menor número. Desse modo, tem-se

[...] paridade aparente, pois os representantes do governo, normalmente servidores que atuam no Executivo ou Legislativo, possuem mais conhecimento sobre o funcionamento da administração pública, o que não acontece com boa parte dos representantes da sociedade civil, que são subjugados, muitas vezes, a uma condição de silêncio (ALVES, 2011, p. 45). 
Percebe-se, portanto, que, mesmo o Estado abrindo-se à participação da sociedade civil, ele mesmo se organiza tendo em vista o cumprimento de seus estritos propósitos. A pesquisa revelou, dentre outros aspectos que, embora a formação dos conselheiros, predomina a centralização de poder e as investidas do sistema para controle das ações de suas organizações. Por outro lado, essa mesma formação, conforme Cury (2006), aponta para possibilidades de transformação na perspectiva do atendimento das demandas sociais e de direitos constitucionais.

\section{Conselhos da Região do Triângulo e Alto Paranaíba (MG) e a questão da representatividade}

A democracia ocidental tem como marca central a representatividade, o que caracteriza, no Brasil, seus processos de democratização, tendo como base as relações participativas oficializadas, ou seja, os canais legítimos de participação, nos quais encontram-se aquelas instituições de apoio educacional, no caso deste trabalho, os Conselhos Municipais de Educação.

Conforme relatados na introdução, foram realizados quatro encontros nacionais sobre os conselhos municipais de educação (os ENCMEs). O quarto encontro, ocorrido em Uberaba, atingiu as regiões do Triângulo Mineiro e do Alto Paranaíba, em Minas Gerais, contando com 110 inscritos. Foram distribuídos 100 questionários, dos quais retornaram 31, o que representa uma porcentagem significativa de participação na enquete sobre a atuação dos conselheiros nos seus respectivos Conselhos Municipais de Educação.

Embora o recolhimento das enquetes tenha atingido um número significativo para efeito da pesquisa é digno de se registrar que $70 \%$ não responderam ao solicitado, o que indica um padrão normal de retorno às pesquisas empíricas realizadas por meio de questionários no Brasil, distribuída, seja materialmente, seja virtualmente. Ora, isso indica que os sujeitos recusam-se a responder de forma ativa ou passiva, se recusando por não acreditar que a pesquisa traga algum resultado estimulante 
para determinadas práticas ou, de forma passiva, devido ao acúmulo de funções e de "coisas mais importantes" a realizar. De qualquer forma, a contribuição dos trinta e um questionários apresentou dados significativos que podem expressar-se na leitura da realidade local e global. O questionário foi distribuído em um evento no qual o público específico eram os conselheiros de educação municipal, resultando os dados que seguem.

Dos 31 participantes que responderam a enquete, 30 eram graduados, tendo um sujeito que era portador de diploma do Ensino Médio. Daqueles 30, havia 4 sujeitos com pós-graduação strictu sensu e 8 com latu sensu. Os educadores responderam que atuavam enquanto Assessor Técnico do CME (1), Assessor Administrativo da SMEd (2), Diretores de Escola foram 2; por sua vez, 9 informaram atuar enquanto professores; supervisores educacionais ou escolares eram 3 e declararam ser Secretários Municipais de Educação 5 deles.

Responderam, ainda, que estavam trabalhando no magistério entre 10 e 16 anos ( 5 deles), entre 20 e 25 foram 9 respondentes e entre 30 a 35 foram 9 informantes. Um destes educadores estava no magistério há 45 anos.

Outra questão solicitava se eram ou tinham sido conselheiros municipais de educação. Dos pesquisados, 19 responderam que eram conselheiros atualmente e dez informaram não ser. Indagados se já tinham sido conselheiros, 6 responderam positivamente, enquanto 12 responderam que nunca tinham sido.

Tais questões foram importantes para saber da atuação e experiência dos participantes do IV ENCME, pois nossa hipótese era a de que tais respostas nos dariam pistas para problematizar o grau de participação e de representatividade dos conselheiros, o que de fato ocorreu, pois, tempo de magistério e formação acadêmica possibilitam mais e melhores oportunidades de assunção a cargos de direção.

Em outra bateria de questões, já buscando qualificar a participação e as respostas dos participantes do IV ENCME foi indagado qual era a função (cargo atual) que exercia o presidente do CME de cada cidade. Um dos participantes respondeu que o presidente era representante do executivo municipal, cinco responderam que eram coordenador ou 
supervisor pedagógico, outro informou que não sabia; quatro responderam que eram diretores de escola, dois que eram professores da Educação Básica, três que eram professores da Educação Superior, e treze indicaram que eram os respectivos Secretários Municipais de Educação. Esta questão foi muito importante pois implicava o grau de relacionamento entre o órgão Executivo, no caso a SMEd, e o órgão colegiado, no caso o Conselho. No Brasil ainda é significativo o número de Secretários de Educação que é, ao mesmo tempo, presidente do CME. Algo que tem sido criticado e combatido em nome dos preceitos democráticos, entretanto que perdura enquanto possibilidade de exercício de controle das SMEd sobre os CMEs.

Outra pergunta, que foi construída no mesmo tom problematizador, foi sobre a atuação e representatividade dos conselheiros e solicitava informações sobre como o Conselho foi composto. Segundo as respostas obtidas na questão, 17 participantes responderam que era composto por eleição, outros doze informaram que por indicação do prefeito, enquanto 9 informaram que era composto por indicação do Secretário de Educação. Ainda, quatro responderam que era por indicação dos vereadores, enquanto 9 por indicação da comunidade. Como a questão era cumulativa, ou seja, cada participante poderia responder cinco itens, além do sexto, composto pela opção outros, o número expressa ser maior que o conjunto de respondentes. Na opção outros ocorreram respostas como: indicação por ONGs (9) e outras instituições/entidades, como o CMDCA, o Conselho Tutelar (3).

Se a forma de composição indica perspectivas participantes e de representação, o número de conselheiros de cada conselho não obedece a uma regra formal. Entretanto, podemos, pela experiência acumulada nos estudos sobre conselho ${ }^{2}$, indicar que um número ínfimo de composição ou um número elevado de membros pode travar qualitativamente as discussões e, quando for o caso, as deliberações dos Conselhos.

Tal item foi constituído da seguinte forma: ao serem indagados sobre o número de participantes dos respectivos conselhos de suas cidade,

${ }^{2}$ Entre os estudos que focam a temática podem ser consultados Lima, 2001 e Lima, 2017. 
2 educadores informaram que seus conselhos tinha de 1 a 5 membros, enquanto outros 3 informaram que tinha de 6 a 10 membros, 6 indicaram que tinham de 11 a 15 membros, 11 que tinham de 15 a 20 conselheiros, dois indicaram que tinham de 20 a 25 e finamente 1 indicou que tinha 36 conselheiros. A forma de composição e representatividade é compreendida, de maneira geral, em um modelo equivocado, tratando-se a paridade de forma quantitativa, quando a mesma diz respeito ao formato qualitativo, pois paridade "não é uma questão apenas numérica, mas das condições de uma certa igualdade no acesso à informação, disponibilidade de tempo, etc." (GOHN, 2006, p. 9).

Pelas discussões realizadas nos conselhos pode-se deduzir que os mesmos tiveram seu papel ampliado de deliberativo para propositivo e de formação de opiniões. Isto ocorre porque, dentre outros fatores, a maior parte dos municípios (22 dos 31 respondentes) não constituíram seus respectivos sistemas municipais de educação. Os conselhos perdem então sua funcionalidade clássica de se constituir em espaço deliberativo, consultivo, informativo e fiscalizador, passando a assimilar papéis propositivos e mobilizadores.

\section{Considerações finais}

Podemos concluir afirmando que os Conselhos de educação no Brasil não se constituíram ainda de forma a deliberar politicamente sobre os rumos da educação municipal, salvo raras exceções, como um órgão apêndice das SMEd. Ainda, pode-se afirmar que os Conselhos não são vistos enquanto uma instituição colaborativa e crítica das gestões municipais, com um papel relevante para a transformação educativa, social e cultural do Município, mas enquanto órgãos que podem "prejudicar" a política municipal, como esta tem sido recorrentemente praticada no Brasil: enquanto marcas de governo.

É relevante ressaltarmos que os Conselhos de Educação fazem parte da superestrutura do Estado, e estão inseridos nos sistemas de ensino 
como mecanismos de gestão colegiada. Neste sentido, estes possuem função primeira a efetivação do controle social da educação de qualidade para todos e a formulação das políticas educacionais. Assim, são espaços profícuos de inovação das políticas públicas, pois são mediadores entre a sociedade civil organizada e os organismos governamentais. Para Gohn (2002, p. 21) "são frutos de demandas populares e de pressões da sociedade civil pela redemocratização do país e de conquistas de movimentos sociais”.

Desde a Constituição de 1988 os Conselhos estão previstos como instrumentos de expressão e representação da população, juridicamente se constituindo como órgãos públicos vinculados ao poder Executivo. Sua finalidade é de discutir, deliberar, assessorar, acompanhar e normatizar os assuntos relacionados a políticas públicas, buscando garantir os direitos da população.

Os CMEs representam forças sociais organizadas que buscam colaborar para o fortalecimento dos sujeitos políticos. Cury (2006, p. 41) destaca que "[...] é, antes de tudo, um órgão público voltado para garantir, na sua especificidade, um direito constitucional da cidadania”. Em sendo desta forma, o conselheiro, ou mesmo daquele que integra esse órgão, tem como referência o interesse público, no sentido de atender às necessidades dos sujeitos que buscam seus direitos com relação à educação escolar.

Ocupando importante lugar no que diz respeito à organização do ensino, cabe ao CME priorizar as competências e estabelecer ações que verdadeiramente assegurem o direito da cidadania, o que contribui diretamente para a democracia.

Deste modo, o Conselho Municipal de Educação possui objetivos e metas para com a sociedade possibilitando em seu âmbito um debate que leve em conta a participação dos sujeitos de todas as classes trabalhadoras. Debater, problematizar e discutir questões relevantes para compreensão da qualidade educacional se faz importante a partir de uma análise democrática que pretende ser participativa.

É nessa perspectiva que devemos pensar no aspecto do Conselho Municipal de Educação, sendo um órgão onde todos possuem o direito de opinar e contribuir para a construção de práticas democráticas, não apenas atribuições e questões burocráticas, administrativas e econômicas. $\mathrm{O}$ 
grande desafio consiste em que os conselhereiros precisam desenvolver um poder analítico, opinando quanto ao direcionamento nas diversas instâncias que abarcam o conselho, o que sugere a superação da mera representatividade dos segmentos e da participação instrumental.

Demo (1999) expõe que a participação social representa um processo de conquista, pautada em canais de diálogo, interação e organização. Os conselhos, assim como outras instituições de caráter similar, são representativos e compreendem uma estrutura de determinação social que passa por diversos campos (políticos, econômicos e sociais).

\section{Referências}

ALVES, E. F. Conselhos Municipais de Educação em Goiás: historicidade, movimentos e possibilidades. 209f. Dissertação (Mestrado em Educação) — Programa de Pós-Graduação em Educação, Faculdade de Educação, Universidade Federal de Goiás, Goiânia, 2011.

AVRITZER, L.; PEREIRA, M. de L. D. Democracia, Participação e Instituições Híbridas. Teoria e Sociedade: Instituições Hibridas e Participação no Brasil e na França, Número especial, p.16-41, 2005.

BEHRING, E. R.; BOSCHETTI, I. Política social: fundamentos e história. 9.ed. São Paulo: Cortez, 2011.

CURY, C. R. J. Conselhos de educação: fundamentos e funções. Revista Brasileira de Política e Adaministração da Educação, v. 22, n. 1, p. 41-67, jan./jun, 2006.

DEMO, P. Participação é conquista: noções de política social participativa. 4. ed. São Paulo: Cortez, 1999.

DURIGUETTO, M. L. Sociedade civil e democracia: um debate necessário. São Paulo: Cortez, 2007.

ENGELS, F. Introdução à Guerra Civil na França, de Karl Marx. In: MARX, K. A guerra civil na França. São Paulo: Boitempo, 2011. 
FERNANDES, F. A revolução burguesa no Brasil: ensaio de interpretação sociológica. 2.ed. Rio de Janeiro: Zahar Editores, 1976.

GOHN, M. da G. Conselhos gestores na política urbana e participação popular. Cadernos Metrópole, n. 7, 2002, p. 9-31.

GOHN, M. da G. Conselhos gestores e gestão pública. Ciências Sociais Unisinos, v. 42, n. 1, p. 5-11, jan./abr. 2006.

IASI, M. Política, Estado e ideologia na trama conjuntural. São Paulo: ICP, 2017.

LIMA, A. B. de. Conselhos Municipais na educação: perspectivas de democratização da política educacional municipal. In: I SEMINÁRIO INTERNACIONAL DE EDUCAÇÃO, 2001, Cianorte. Anais: I Seminário internacional de Educação. Cianorte: TAC Multimídia Ltda, 2001. v. I.

LIMA, A. B. de. (Org.). Estado e controle social no Brasil. Uberlândia: EDUFU, 2011.

LIMA, A. B. de. Conselhos Municipais de Educação no Brasil e a construção da concepção de qualidade. In: LIMA, A. B. de (Org.). CMEs no Brasil - qualidade social e política da educação. São Paulo: Alínea, 2017.

MASCARO, A. L. Estado e forma política. São Paulo: Boitempo, 2013.

MÉSZÁROS, I. A montanha que devemos conquistar. São Paulo: Boitempo, 2015.

Recebido: 03/04/2018

Received: 04/03/2018

Recibido: 03/04/2018

Aprovado: $25 / 05 / 2018$

Approved: 05/25/2018

Aprobado: 25/05/2018 